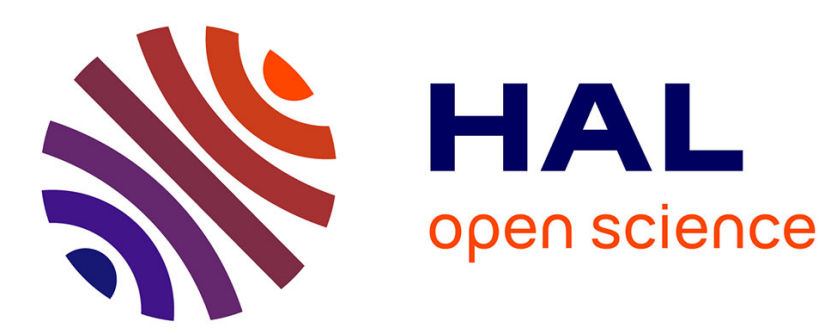

\title{
New Technology, Human Capital and Growth in a Developing Country
}

Cuong Le Van, Tu-Anh Nguyen, Manh-Hung Nguyen, Thai Bao Luong

\section{To cite this version:}

Cuong Le Van, Tu-Anh Nguyen, Manh-Hung Nguyen, Thai Bao Luong. New Technology, Human Capital and Growth in a Developing Country. Mathematical Population Studies, 2010, 17 (4), pp.215241. 10.1080/08898480.2010.514852 . halshs-00470647

\section{HAL Id: halshs-00470647 https://shs.hal.science/halshs-00470647}

Submitted on 7 Apr 2010

HAL is a multi-disciplinary open access archive for the deposit and dissemination of scientific research documents, whether they are published or not. The documents may come from teaching and research institutions in France or abroad, or from public or private research centers.
L'archive ouverte pluridisciplinaire HAL, est destinée au dépôt et à la diffusion de documents scientifiques de niveau recherche, publiés ou non, émanant des établissements d'enseignement et de recherche français ou étrangers, des laboratoires publics ou privés. 


\title{
New Technology, Human Capital and Growth in a Developing Country
}

\author{
Cuong Le Van * \\ Université Paris 1 Panthéon-Sorbonne, CNRS, Paris School of Economics \\ Tu-Anh Nguyen \\ Université Paris 1 Panthéon-Sorbonne, CNRS \\ Manh-Hung Nguyen \\ Université Toulouse 1, Toulouse School of Economics, LERNA \\ Thai Bao Luong \\ National Economics University, Hanoi
}

November 18, 2009

\begin{abstract}
In a developing country with three sectors: consumption goods, new technology, and education, the productivity of the consumption goods depends on a new technology and skilled labor used to produce this new technology. There can be three stages of economic growth. In the first stage the country concentrates on the production of consumption goods; in the second the country must import both physical capital and new technology capital to produce consumption goods and new technology; in the third the country must import capital and invest in the training and education of high skilled labor.
\end{abstract}

Keywords: Optimal growth model; New technology capital; Human Capital; Developing country.

JEL Classification: D51, D90, E13

\section{Introduction}

Sources of technical progress can be domestic or international, though, some economists believe that developed countries innovate and export technology

\footnotetext{
${ }^{*}$ Corresponding author. The authors are grateful to two anonymous referees for their helpful remarks and suggestions. The author thank also the Editor for the editorial corrections.
} 
while developing countries import and copy ( Baumol 1986, Dowrick and Nguyen 1989, Gomulka 1991, Young 1995, Lall 2000, Lau \& Park 2003, Barro and Salai-Martin 2004). Developing countries need to adopt technology from the international market in order to improve their productivity (Romer 1997, 1990). These countries also need to care for their human capital (Lucas 1988).

Developing countries must choose between investing in technological and human capital. Barro (1997), Barro and Sala-i-Martin (2004), Eaton and Kortum (2000), Keller (2001), Kumar (2003), Kim and Lau (1994), Lau and Park (2003) showed that developing countries are not convergent and that a certain level in capital accumulation is necessary to hope for economic growth.

Galor and Moav (2004) consider the optimization of investment in physical and human capital from the point of view of capital suppliers. They assumed that the technology for producing human capital is not that good so that, when physical capital is rare, the rate of return to physical capital is higher than the one to human capital. It is, then better to invest in physical than human capital. Accumulation gradually reduces the rate of return to physical capital where the rate of return to human capital increases. There is some time, when investment in human capital supercedes physical capital as the main engine of growth.

In contrast to Galor and Moav (2004), we consider the optimal investments in human and physical capital on the demand of capital. In Galor and Moav (2004) the source of growth is inter-generational transfer, in Bruno et al. (2009) and here the source of growth is the ability of Total Factor Productivity (TFP) generation.

Bruno et al. (2009) specify the conditions under which a developing country can decide optimally either to concentrate whole resources on the accumulation of physical capital, or to devote a portion of its national wealth to import technological capital. These conditions are related to the level of wealth and endowment in human capital and thresholds at which the country switches to another stage of development. However, they do not fully explore the role of 
education which contributes to the accumulation of human capital.

We extend their model by introducing education. We show that after a critical value of wealth the country ought to invest in new technology. The country can either keep its existing technology or invest in new technology capital in order to produce new technology. It is always optimal for the country to use new technology. We show further that under certain conditions the country can either invest in new technology and high education or only invest in new technology. We shall determine the level of wealth at which the decision to invest in training and education has to be made. We shall show that the critical value of wealth is inversely related to productivity in the new technology sector, to the total number of skilled workers, and to the spill-over effectiveness of the new technology sector on the sector of consumption goods but proportionally related to the price of the new capital of the technology. We shall determine the optimal share of the investment in physical capital, new technology capital, and human capital formation on the long-run growth path. Our result on the replacement of physical by human capital accumulation in the course of development is consistent with those of Galor and Moav (2004).

Our two main results are: (1) the richer a country, the more money is invested in new technology, training, and education, (2) the share of investment in human capital increases with wealth while the share for physical and new technology capitals decrease. In any case, the economy grows unabated. In contrast with Bruno et al. (2009), we shall confront our model with empirical data.

\section{$2 \quad$ Model}

Consider a three-sector economy constituted of a domestic sector which produces an aggregate good $Y_{d}$, a new technology sector with output $Y_{e}$, and an education sector characterized by a function $h(T)$ where $T$ is the total spend- 
ing in education. The domestic sector uses $Y_{e}$ to increase its total productivity. The production functions are Cobb-Douglas: $Y_{d}=\Phi\left(Y_{e}\right) K_{d}^{\alpha_{d}} L_{d}^{1-\alpha_{d}}$ and $Y_{e}=$ $A_{e} K_{e}^{\alpha_{e}} L_{e}^{1-\alpha_{e}}$ where $\Phi($.$) is a non-decreasing function satisfying \Phi(0)=x_{0}>0$, $K_{d}, K_{e}, L_{d}, L_{e}$, and $A_{e}$ stand for physical capital, technological capital, lowskilled labor, high-skilled labor and total productivity, $0<\alpha_{d}<1,0<\alpha_{e}<$ 1.This specification implies that productivity growth is orthogonal to physical capital accumulation (Collins et al. 1996, Lau and Park 2003).

The price of capital goods is the numéraire in terms of consumption goods. The price of the new technology sector is higher and equal to $\lambda \geq 1$. Labor mobility between the sectors is impossible and wages are exogenous.

$S$ being the available spending in capital goods and human capital,

$$
K_{d}+\lambda K_{e}+p_{T} T=S
$$

For simplicity, $p_{T}=1, T$ is measured in capital goods. The budget constraint of the economy is

$$
K_{d}+\lambda K_{e}+T=S
$$

where $S$ is the wealth of the country in terms of consumption goods.

The social planner maximizes

$$
\max Y_{d}=\underset{\left(K_{d}, K_{e}, T, L_{d}, L_{e}\right)}{\operatorname{Max}} \Phi\left(Y_{e}\right) K_{d}^{\alpha_{d}} L_{d}^{1-\alpha_{d}}
$$

subject to

$$
\left\{\begin{array}{l}
Y_{e}=A_{e} K_{e}^{\alpha_{e}} L_{e}^{1-\alpha_{e}} \\
K_{d}+\lambda K_{e}+T=S, \\
0 \leq L_{e} \leq L_{e}^{*} h(T), \\
0 \leq L_{d} \leq L_{d}^{*}
\end{array}\right.
$$

where $h$ represents the technology to produce human capital; $L_{e}^{*}$ is the total 
number of skilled workers in the new technology sector; $L_{e}$ is effective labor; $L_{d}^{*}$ is the total number of non-skilled workers in the domestic sector.

$h($.$) is an increasing concave function with h(0)=h_{0}>0, Y_{d}$ is a concave function of investment in education (marginal returns to education are diminishing, Psacharopoulos, 1994). Let

$$
\Delta=\{(\theta, \mu): \theta \in[0,1], \mu \in[0,1], \theta+\mu \leq 1\}
$$

From the budget constraint, we define $(\theta, \mu) \in \Delta$ :

$$
\lambda K_{e}=\theta S, K_{d}=(1-\theta-\mu) S \text { and } T=\mu S .
$$

The objective function being strictly increasing, at the optimum, the constraints are binding. Let $L_{e}=L_{e}^{*} h, L_{d}=L_{d}^{*}$, then the problem is:

$$
\operatorname{Max}_{(\theta, \mu) \in \Delta} \Phi\left(r_{e} \theta^{\alpha_{e}} S^{\alpha_{e}} h(\mu S)^{1-\alpha_{e}}\right)(1-\theta-\mu)^{\alpha_{d}} S^{\alpha_{d}} L_{d}^{* 1-\alpha_{d}}
$$

where $r_{e}=\frac{A_{e}}{\lambda^{\alpha_{e}}} L_{e}^{* 1-\alpha_{e}}$.

Let

$$
\psi\left(r_{e}, \theta, \mu, S\right)=\Phi\left(r_{e} \theta^{\alpha_{e}} S^{\alpha_{e}} h(\mu S)^{1-\alpha_{e}}\right)(1-\theta-\mu)^{\alpha_{d}} L_{d}^{* 1-\alpha_{d}}
$$

The problem is equivalent to

$$
\underset{(\theta, \mu) \in \Delta}{\operatorname{Max}} \psi\left(r_{e}, \theta, \mu, S\right)
$$

$\psi$ is continuous in $\theta$ and $\mu$, there exist optimal solutions. Denote

$$
F\left(r_{e}, S\right)=\operatorname{Max}_{(\theta, \mu) \in \Delta} \psi\left(r_{e}, \theta, \mu, S\right)
$$


If $\Phi(x)$ is constant in an initial phase and increasing linearly afterwards:

$$
\Phi(x)=\left\{\begin{array}{l}
x_{0} \text { if } x \leq X \\
x_{0}+a(x-X) \text { if } x \geq X, a>0 .
\end{array}\right.
$$

The threshold in function $\Phi$ may be interpreted either as a setup cost as in Azariadis and Drazen (1990), or a minimum level of adoption of new technology which is necessary in order for them to impact the economy. Alternatively a productive innovation cannot be realized without necessary non-productive knowledge, the critical level X can be understood as cumulative level of nonproductive knowledge that is necessary for the first productive innovation comes out. The surveys by Lau and Park (2003) and Young (1995) show that between mid of 1960s and 1986 East Asian economies enjoyed high growth rate but technological progress plays no role at all. Our assumption on $\Phi$ can be justified by these surveys.

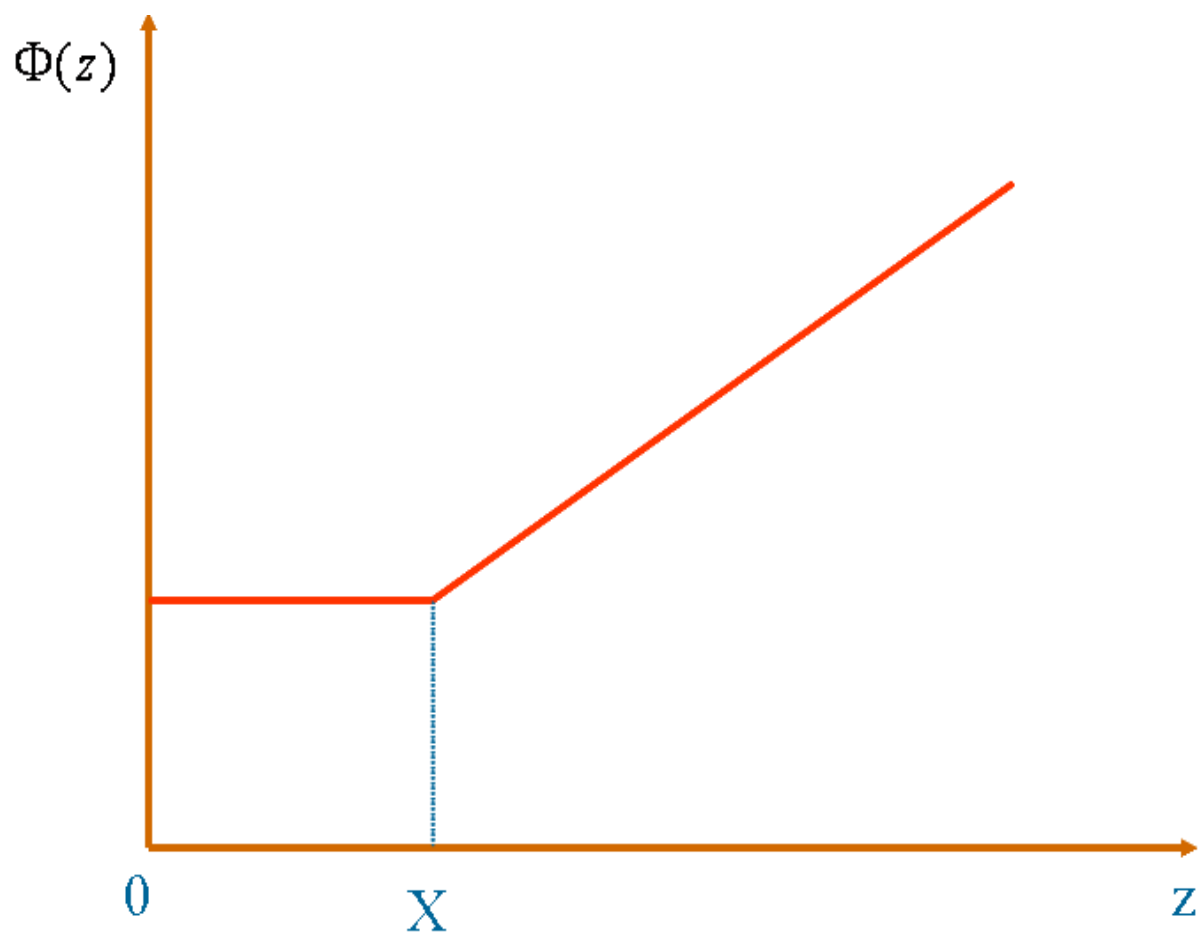

Figure 1: Technological progress in the production of consumption good 
By the Theorem of Maximum, $F$ is continuous and $F\left(r_{e}, S\right) \geq x_{0} L_{d}^{* 1-\alpha_{d}}$. Proposition 1 establishes the existence of a threshold.

Proposition 1 There exists $S^{c}$ such that, if $S<S^{c}$ then $\theta(S)=0$ and $\mu(S)=$ 0 , and if $S>S^{c}$ then $\theta(S)>0$.

Proof: In appendix 1.

Remark 1 If $S>S^{c}$ then

$$
Y_{e}>X \text { and } \Phi\left(Y_{e}\right)=x_{0}+a\left(Y_{e}-X\right)
$$

Proposition 2 shows that, when the quality of the training technology (measured by the marginal productivity $h^{\prime}(0)$ at the origin) is very high, then for any $S>S^{c}$ the country invests both in the new technology and in human capital. When $h^{\prime}(0)$ is finite, the country no longer has to invest in human capital when $S>S^{c}$, but does it if it is sufficiently rich. If $h^{\prime}(0)$ is low, the country does not invest in human capital when $S$ belongs to some interval $\left(S^{c}, S^{m}\right)$.

Proposition 2 1. If $h^{\prime}(0)=+\infty$, then for all $S>S^{c}, \theta(S)>0, \mu(S)>0$.

2. If $h^{\prime}(0)<+\infty$, then there exists $S^{M}$ such that $\mu(S)>0, \theta(S)>0$ for every $S>S^{M}$.

3. There exists $\alpha>0$ such that, if $h^{\prime}(0)<\alpha$, there exists $S^{m}>S^{c}$ such that $\mu(S)=0, \theta(S)>0$ for $S \in\left[S^{c}, S^{m}\right]$.

Proof: in Appendix 1.

Proposition 3 states that there exists a threshold above which $\theta(S)$ and $\mu(S)$ are positive.

Proposition 3 If $h^{\prime}(0)<+\infty$, then there exists $\widehat{S} \geq S^{c}$ such that:

(i) $S \leq \widehat{S} \Rightarrow \mu(S)=0$,

(ii) $S>\widehat{S} \Rightarrow \mu(S)>0, \theta>0$. 
Proof: in Appendix 1.

Let us recall that $r_{e}=\frac{A_{e} L_{e}^{*\left(1-\alpha_{e}\right)}}{\lambda^{\alpha_{e}}}=A_{e} L_{e}^{*}\left(L_{e}^{*} \lambda\right)^{-\alpha_{e}}$ where $A_{e}$ is the productivity of the new technology sector, $\lambda$ the price of the new technology capital, $\alpha_{e}$ the capital share in the new technology production sector, and $L_{e}^{*}$ the total number of skilled workers. The productivity function of the consumption goods sector is $\Phi(x)=x_{0}+a(x-X)$ if $x \geq X$. The spill-over indicator $a>0$ represents the level of social and institutional capital. It indicates the effectiveness of the new technology product on the productivity. We will show in Proposition 4 that the critical value $S^{c}$ decreases when $r_{e}$ increases, when the productivity $A_{e}$ or the total number of skilled workers increase, when the price of the new technology capital $\lambda$ decreases, when the share of capital in the new technology sector $\alpha_{e}$ decreases (more human-capital intensive), or when the spill-over indicator $a$ increases. Initiating investment into the new technology sector is favoured by: $(i)$ the potential productivity in the new technology sector; (ii) the total number of skilled workers; (iii) the price of the new technology; (iv) and the intensity of human capital in the new technology sector and of spill-over effects.

Proposition 4 Let $\theta^{c}=\theta\left(S^{c}\right), \mu^{c}=\mu\left(S^{c}\right)$. Then

(i) $\mu^{c}=0, \theta^{c}$ does not depend on $r_{e}$.

(ii) $S^{c}$ decreases if a or $r_{e}$ increases.

Proof: in Appendix 1.

Proposition 5 shows that the optimal shares $\theta$ and $\mu$ converge when $S$ goes to infinity. The ratio of spendings on human capital to $S$ and the ratio of spendings on new technology and education to $S$ increase when $S$ increases.

Proposition 5 If $h(z)=h_{0}+b z$, with $b>0$, then the optimal shares $\theta(S)$ and $\mu(S)$ converge to $\theta_{\infty}$ and $\mu_{\infty}$ when $S$ goes to $+\infty$. Consider $\widehat{S}$ in Proposition 3. Then 


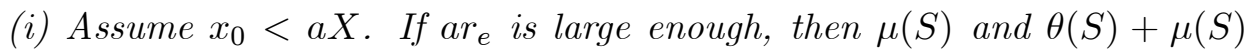
increase when $S$ increases.

(ii) If $x_{0} \geq a X$, then $\mu(S)$ and $\theta(S)+\mu(S)$ increase when $S$ increases.

Proof: Write $\theta, \mu$ instead of $\theta(S)$ and $\mu(S)$. Consider $\widehat{S}$ in Proposition 3 . When $S \leq \widehat{S}$, then $\mu=0$ (Proposition 3). When $S>\widehat{S},(\theta, \mu)$ satisfy Eq. (48) and (49) which can be written as:

$$
\theta\left(\alpha_{d}+\alpha_{e}\right)=-\alpha_{e} \mu+\alpha_{e}-\frac{\alpha_{d}\left(x_{0}-a X\right) \alpha_{e}{ }^{-\alpha_{e}}}{a r_{e} S\left(1-\alpha_{e}\right)^{1-\alpha_{e}} b^{1-\alpha_{e}}}
$$

and

$$
\theta\left(1-\alpha_{e}\right)=\alpha_{e} \mu+\frac{\alpha_{e} h_{0}}{b S}
$$

We obtain

$$
\theta\left(1+\alpha_{d}\right)=\alpha_{e}-\frac{\alpha_{d}\left(x_{0}-a X\right) \alpha_{e}{ }^{-\alpha_{e}}}{a r_{e} S\left(1-\alpha_{e}\right)^{1-\alpha_{e}} b^{1-\alpha_{e}}}+\frac{h_{0} \alpha_{e}}{b S}
$$

and

$$
\mu=\theta\left(\frac{1}{\alpha_{e}}-1\right)-\frac{h_{0}}{b S}
$$

Thus

$$
\theta+\mu=\frac{1}{1+\alpha_{d}}\left(1-\frac{\alpha_{d}}{\alpha_{e}} \frac{\left(x_{0}-a X\right) \alpha_{e}{ }^{-\alpha_{e}}}{a r_{e} S\left(1-\alpha_{e}\right)^{1-\alpha_{e}} b^{1-\alpha_{e}}}\right)-\frac{\alpha_{d}}{1+\alpha_{d}} \frac{h_{0}}{b S}
$$

and:

$$
\frac{\mu}{1-\alpha_{e}}=\frac{1}{1+\alpha_{d}}\left(1-\frac{\alpha_{d}}{\alpha_{e}} \frac{\left(x_{0}-a X\right) \alpha_{e}{ }^{-\alpha_{e}}}{a r_{e} S\left(1-\alpha_{e}\right)^{1-\alpha_{e}} b^{1-\alpha_{e}}}\right)-\left(\frac{\alpha_{d}}{1+\alpha_{d}}+\frac{\alpha_{e}}{1-\alpha_{e}}\right) \frac{h_{0}}{b S}
$$

If $x_{0} \geq a X, \theta+\mu$ and $\mu$ increase with $S$. If $x_{0}<a X$, when $a r_{e}$ is large enough, $\theta+\mu$ and $\mu$ increase with $S$. When $S$ goes to $+\infty, \theta$ converges to $\theta_{\infty}=\frac{\alpha_{e}}{1+\alpha_{d}}$ and $\mu$ converges to $\mu_{\infty}=\frac{1-\alpha_{e}}{1+\alpha_{d}}$. 


\section{Dynamic Model}

The representative consumer lives infinitely and has an intertemporal utility function with discount factor $\beta<1$. At each period, she uses her savings to invest in physical capital, in new technology capital or in human capital. The depreciation rate of capital equals 1 and the population growth rate is 0 , $L_{e, t}^{*}=L_{e}^{*}$ and $L_{d, t}^{*}=L_{d}^{*}$.

The social planner solves the dynamic growth model:

$$
\max _{\left(c_{t}\right)_{t}} \sum_{t=0}^{\infty} \beta^{t} u\left(c_{t}\right)
$$

subject to:

$$
\left\{\begin{array}{l}
c_{t}+S_{t+1} \leq \Phi\left(Y_{e, t}\right) K_{d, t}^{\alpha_{d}} L_{d, t}^{1-\alpha_{d}} \\
Y_{e, t}=A_{e} K_{e, t}^{\alpha_{e}} L_{e, t}^{1-\alpha_{e}} \\
K_{d, t}+\lambda K_{e, t}+T_{t}=S_{t} \\
0 \leq L_{e, t} \leq L_{e}^{*} h\left(T_{t}\right), 0 \leq L_{d, t} \leq L_{d}^{*}
\end{array}\right.
$$

the initial resource $S_{0}$ is given

The problem is equivalent to

$$
\begin{aligned}
\max _{\left(c_{t}\right)_{t}} & \sum_{t=0}^{\infty} \beta^{t} u\left(c_{t}\right) \\
\text { s.t } & \forall t, c_{t}+S_{t+1} \leq H\left(r_{e}, S_{t}\right),
\end{aligned}
$$

with

$$
H\left(r_{e}, S\right)=F\left(r_{e}, S\right) S^{\alpha_{d}}
$$

where $r_{e}=\frac{A_{e}}{\lambda^{\alpha_{e}}} L_{e}^{* 1-\alpha_{e}}$, and where $\beta$ is the discount rate for time preference $0 \leq \beta \leq 1$. $H\left(r_{e},.\right)$ is continuous, strictly increasing, and $H\left(r_{e}, 0\right)=0$.

We again use $S^{c}$ defined as:

$$
S^{c}=\max \left\{S \geq 0: F\left(r_{e}, S\right)=x_{0} L_{d}^{* 1-\alpha_{d}}\right\}
$$


where

$$
F\left(r_{e}, S_{t}\right)=\operatorname{Max}_{0 \leq \theta_{t} \leq 1,0 \leq \mu_{t} \leq 1} \psi\left(r_{e}, \theta_{t}, \mu_{t}, S_{t}\right)
$$

H2. The utility function $u$ is strictly concave, strictly increasing, and satisfies the Inada condition: $u^{\prime}(0)=+\infty, u(0)=0, u^{\prime}(\infty)=0$.

At the optimum, the constraints are binding, the initial program is equivalent to:

$$
\begin{array}{ll} 
& \max _{\left(S_{t}\right)_{t}} \sum_{t=0}^{\infty} \beta^{t} u\left(H\left(r_{e}, S_{t}\right)-S_{t+1}\right) \\
\text { s.t } \quad & \forall t, 0 \leq S_{t+1} \leq H\left(r_{e}, S_{t}\right) . \\
& S_{0}>0 \text { is given. }
\end{array}
$$

As in Bruno et al. (2009), we have:

Proposition 6 i) Every optimal path is monotonic.

ii) No optimal trajectory $\left(S_{t}^{*}\right)$ from $S_{0}$ can converge to 0 .

Denote $\theta_{t}^{*}$ the optimal capital shares among the technological capital stock and $\mu_{t}^{*}$ the total spendings for human capital:

$$
\lambda K_{e, t}^{*}=\theta_{t}^{*} S_{t}^{*} \text { and } T_{t}^{*}=\mu_{t}^{*} S_{t}^{*}
$$

Proposition 7 If $h(z)=h_{0}+b z$, with $b>0$ and $\alpha_{e}+\alpha_{d} \geq 1$, and if $a$ or $r_{e}$ are large enough, then the optimal path $\left\{S_{t}^{*}\right\}_{t=1,+\infty}$ tends to infinity when $t$ goes to infinity. Hence:

(i) there exists $T_{1}$ such that

$$
\theta_{t}^{*}>0 \forall t \geq T_{1}
$$


(ii) there exists $T_{2} \geq T_{1}$ such that

$$
\theta_{t}^{*}>0, \mu_{t}^{*}>0, \forall t \geq T_{2}
$$

When $t$ goes to infinity, the sum $\theta_{t}^{*}+\mu_{t}^{*}$ and the share $\mu_{t}^{*}$ increase and converge to values less than 1.

Proof: in Appendix 1.

In the course of economic growth, initially a country invests only in physical capital. When the country reaches a critical level, it must invest not only in physical capital but also in new technology and in high education. Under some mild conditions on the quality of the production of the new technology and on the supply of skilled workers, the share of the investment, in human capital, and in new technology and human capital, increases when the country becomes rich.

Thanks to new technology and human capital, the TFP increases and induces growth, the economy grows unabated.

\section{Results}

King and Rebelo (1993) simulate neoclassical growth models to conclude that contribution of physical capital accumulation plays only a minor role in explaining observed growth rates. They suggest endogenous growth models such as human capital formation or endogenous technical progress. Hofman (1993) examines the economic performances of South Korea, Taiwan and Thailand, Portugal, Spain, France, Germany, Japan, The Netherlands, the UK and US in the twentieth century. He concludes that growth is driven by physical capital accumulation in developing economies, by human capital and technological progress in developed economies. Young (1994), Kim and Lau (1994), Krugman (1994), Collins and Bosworth (1996, p.186) and Lau and Park (2003) claim that 
the economic miracle in East Asia was mostly due to physical capital accumulation and not at all to technological progress. Collins and Bosworth (1996) suggests that "it is possible that the potential to adopt knowledge and technology from abroad depends on a country's stage of development. Growth in the early stages may be primarily associated with physical and human capital accumulation, and significant potential for growth through catchup may only emerge once a country has crossed some development thresholds". On the one hand, Lau and Park (2003) show that the hypothesis of no technological progress in East Asia Newly Industrialized Economies (NIEs) until 1986 cannot be rejected. On the other hand, since 1986 when these economies started investing heavily on R\& D, technological progress has generated significant growth. This fact fact supports our prediction that there exists a threshold for investing in new technology.

In this section we use pooled time-series of educational attainment for 71 non-oil exporting, developing economies compiled by Barro and Lee (2000) and real Gross Domestic Product per head (y) (in purchasing power parity, PPP) of these countries in Penn World Table 6.2 (Heston, et al., 2006) to compute a correlation between human capital and level of development. In Barro and Lee (2000) we use five variables to measure human capital: percentage of labor force with completed primary school $\left(l_{1}\right)$; with completed secondary school $\left(l_{2}\right)$; with completed higher secondary school $\left(l_{3}\right)$; and average schooling years of labor force $(A)$. These data are calculated for every five-year period from 1950 at least, to 2000. Oil exporting countries are excluded from the sample because they have enjoyed a high level of GDP per head.

The two OLS regressions:

$$
\ln y=\alpha+\beta_{1} l_{1}+\beta_{2} l_{2}+\beta_{3} l_{3}+\varepsilon
$$


and

$$
\ln y=\alpha+\gamma_{1} A+\varepsilon
$$

are first tested on a whole sample for checking the stability. Employing rolling regression procedure we detect that estimated coefficients of Eq. (29) and one estimated coefficient in Eq. (28) are negative for all regressions on sub-sample with GDP per head under 1267 USD. Second, Chow break point and forecast tests reject the null hypothesis of equality of regression coefficients in the 2 sub-samples: one with GDP per head under 1267 USD (149 observations), and another with GDP per head over 1267 USD (459 observations).

The results presented in Table 1 show that when the GDP per head is under 1267 USD ( $y$ in PPP and constant price in 2000) the hypothesis of no contribution of human capital to economic growth cannot be rejected, while when $y>1267$ this hypothesis is rejected with a risk of five percentage to be wrong.

Table 1: Contributions of human capital to economic growth

\begin{tabular}{ccccc}
\hline & \multicolumn{2}{c}{ Equation 28 } & \multicolumn{2}{c}{ Equation 29 } \\
\cline { 2 - 5 }$R^{2}$ & $y \leq 1267$ & $y>1267$ & $y \leq 1267$ & $y>1267$ \\
$\bar{n} R^{2}$ & 0.021 & $\mathbf{0 . 3 7 1}$ & 0.0002 & $\mathbf{0 . 4 6 4}$ \\
$\beta_{1}$ & $\sim 0.000(0.005)$ & $0.017(\mathbf{0 . 0 0 3})^{*}$ & & $\mathbf{0 . 4 6 2}$ \\
$\beta_{2}$ & $-0.009(0.012)$ & $0.043(\mathbf{0 . 0 0 7})^{*}$ & & \\
$\beta_{3}$ & $0.092(0.053)$ & $0.028(\mathbf{0 . 0 0 9})^{*}$ & & \\
$\gamma_{1}$ & & & $-0.003(0.018)$ & $0.21(\mathbf{0 . 0 1})^{*}$ \\
\hline Obs & 149 & 459 & 149 & 459 \\
\hline
\end{tabular}

Note: the numbers in the parentheses are standard deviations;

* statistically significant at the level of significance of $5 \%$

When $y>1267$ the coefficients: of the percentage of labor force with com- 
pleted primary school $\left(l_{1}\right)$, of completed secondary school, and of completed higher secondary school are all of expected sign and statistically significant. The results of Eq. (29) confirm the positive contribution of human capital when it is measured by the average total number of schooling years.

By contrast, when $y \leq 1267$, the adjusted $R^{2}$ in Eq. (28) and Eq. (29) are nearly zero, no coefficient is statistically significant. These results imply that human capital plays no role in economic growth, that there is no demand for investing in human capital when income is lower than a critical level.

We examine the total spendings on human capital and new technology in China, South Korea and Taiwan. Does share of human capital and spendings for new technology in total investment $(S)$ in these economies increase?

The data of total spendings in human capital is not directly available. We follow Carsey and Sala-i-Martin (1995) to assume that wages contain a part devoted to finance human capital. This part depends not only on the total number of schooling years but also on-the-job training, job experience, schooling quality, and technological level.

The minimum wage is assumed to be the non-skilled one. The spendings in human capital $\mathrm{EHC}_{t}$ at time $\mathrm{t}$ are:

$$
\mathrm{EHC}_{t}=\mathrm{E}_{t}\left(\mathrm{AW}_{t}-\mathrm{MW}_{t}\right)
$$

where $\mathrm{E}$ is total number of employed workers, AW the mean wage, and MW the minimum wage. The part AW-MW is rewarded for skill.

The new technological capitals are produced in the R\&D sector, then the total spendings in $\mathrm{R} \& \mathrm{D}$ is a proxy for investment in technological capital $\left(\lambda K_{e}\right)$, and the fixed capital formation (if not available, then the formation of gross capital) is a proxy for spendings on $K_{d}$.

For China, the data of AW, GDP, and E are available in the Census and Economic Information Center (CEIC) database from 1952 to 2006. The minimum 
wage in China varies between provinces and within province. The minimum wage for all provinces is available between 2004-2006 from the Ministry of Labor and Social Security of China. Therefore we use the average wage in the sector of farming, forestry, animal husbandry and fishery which use the least human capital and physical capital as a proxy of the minimum wage. From the CEIC database, we come up with a time-series of national minimum wages in China from 1980 to 2006. As data of fixed capital formation in China are not available, we use the data of gross capital formation, which are available in the World Development Indicator (WDI) database of the World Bank. Finally, the statistics for R\&D expenditure in period 1980-2006 are available in statistical yearbooks.

For Taiwan, the data for the total compensation of employees $\left(\mathrm{E}_{t} \mathrm{x} \mathrm{AW}_{t}\right)$, employment $\left(\mathrm{E}_{t}\right)$, fixed capital formation, GDP, and average wage in the manufacturing sector are available in the CEIC database between 1978 and 2006. The minimum wage rates are only available between 1993 and 2006 and in 1984 at the US Department of State ${ }^{1}$. We fill in the missing data between 1983 and 1992 by estimated ones. For that, we assume that the minimum wage (MW) is a concave function of average wage in the manufacturing sector $\left(\mathrm{AW}_{m}\right)$ or more specifically, the ratio of $\frac{\mathrm{MW}}{\mathrm{AW}}$ is linearly correlated with $\mathrm{AW}_{m}$. The OLS regression yields estimations for missing data. The data of $\mathrm{R} \& \mathrm{D}$ expenditure is taken from the National Science Council (2007) and Lau and Park (2003).

For South Korea, the CEIC database provides data of employment (E), compensations for employees (E x AW), fixed capital formation, GDP, and nominal wage index. The minimum wages between 1988 and 2006 are taken from Global Production Network (GPN) (2001) and from the US State Department website. If we assume that between1976 and 1987, the minimal wage changes with the nominal wage index, then we can estimate the total spendings for human capital between 1976 and 1987. The data for the total spendings in R\&D is

\footnotetext{
${ }^{1}$ Cited at the website: http://dosfan.lib.uic.edu/ERC/economics/commercial_guides/Taiwan.html and http://www.state.gov/g/drl/rls/hrrpt/2006/78770.htm
} 
taken from UNESCO.

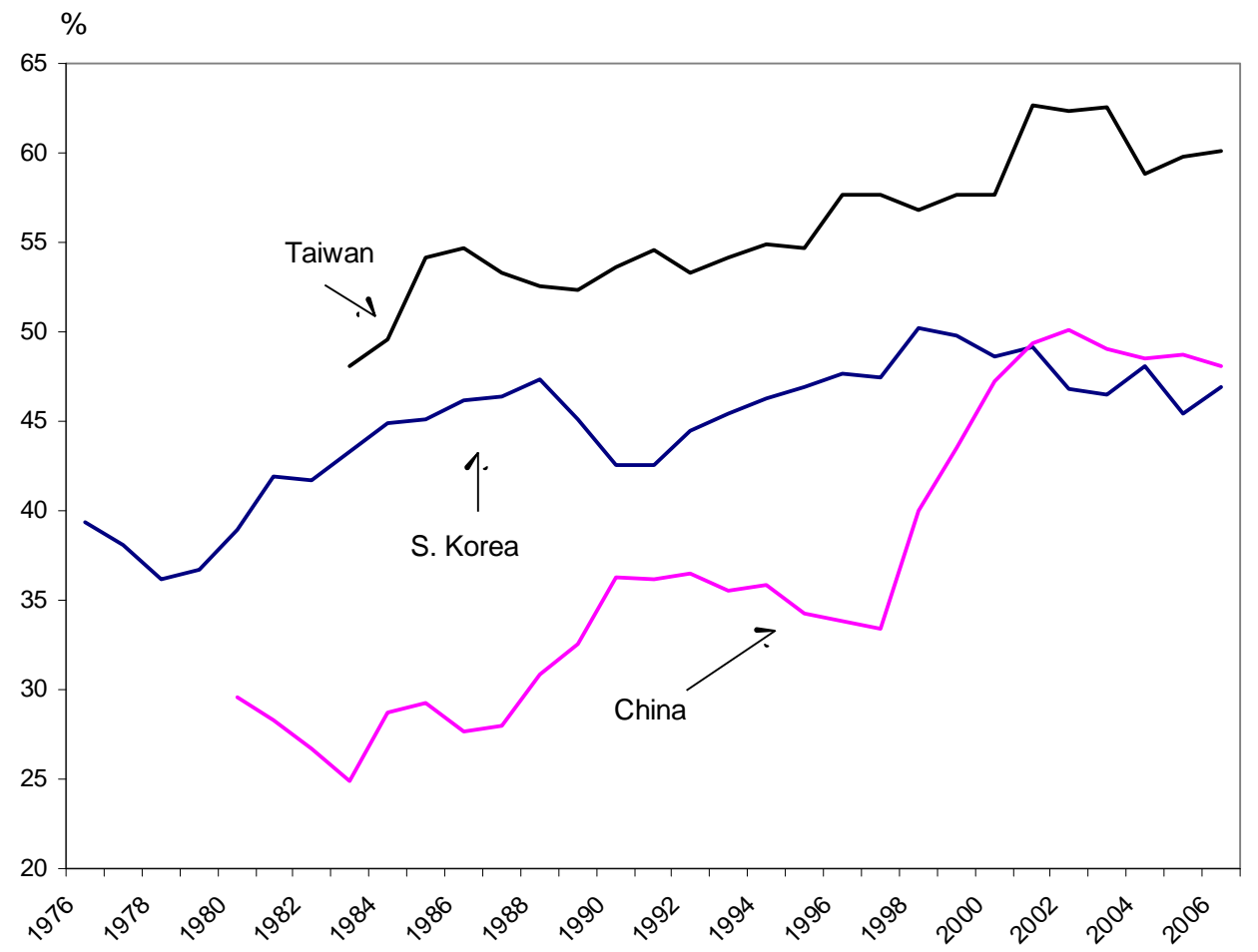

Figure 2: Human capital and R\&D in total available investment

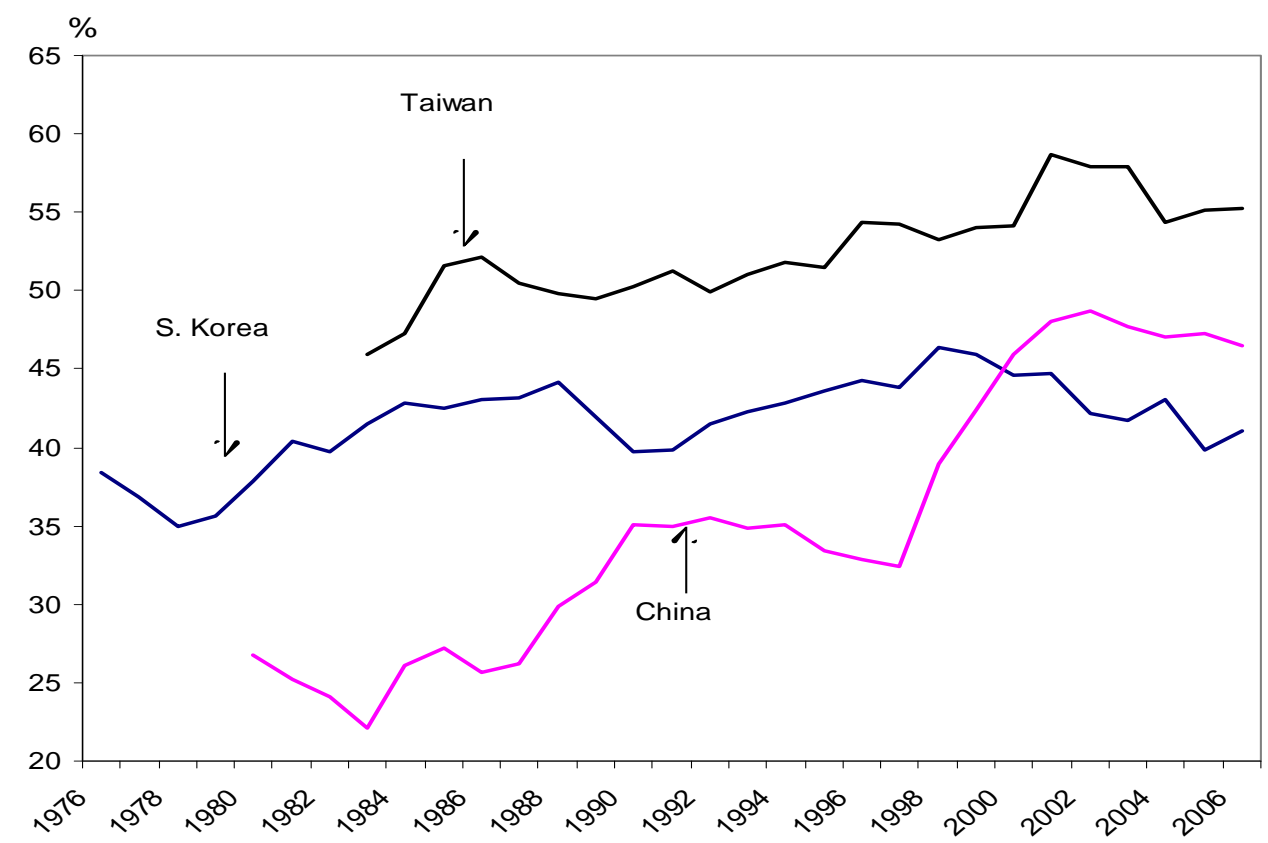

Figure 3: Share of Human Capital in Total available Investment

Figure 2 shows the increasing share of human capital and R\&D in total 
available investment in the three economies. Figure 3 shows the increasing share of human capital in total available investment in Taiwan and China, as well as, although with fluctuation, in South Korea. Our predictions of the shares of human capital and new technology, and of physical capital are consistent with Figures 2 and 3.

If the available budget $S$ for total investment is positively related to GDP, the movement of ratios of $\lambda K_{e}$ and spendings for human capital $T$ to GDP follow the ratios of $\lambda K_{e}$ and $T$ to $S$.

Figures 4, 5 and 6 are consistent with our prediction that both the sum $\mu_{t}+\theta$ of the share of human capital and R\&D and the share of human capital in GDP increase. The Asian crisis of 1997 on investment in human capital and $\mathrm{R} \& \mathrm{D}$ is visible on Figures 4, 5 and 6. China was the least affected, South Korea the most, it had to resort to International Monetary Fund (IMF). South Korea recovered after 1999 keeping a drastic spending policy till the early 2000s. That is why the figure 6 shows a declining trend for both the share of human capital and R\&D, and the share of human capital, after 1997.

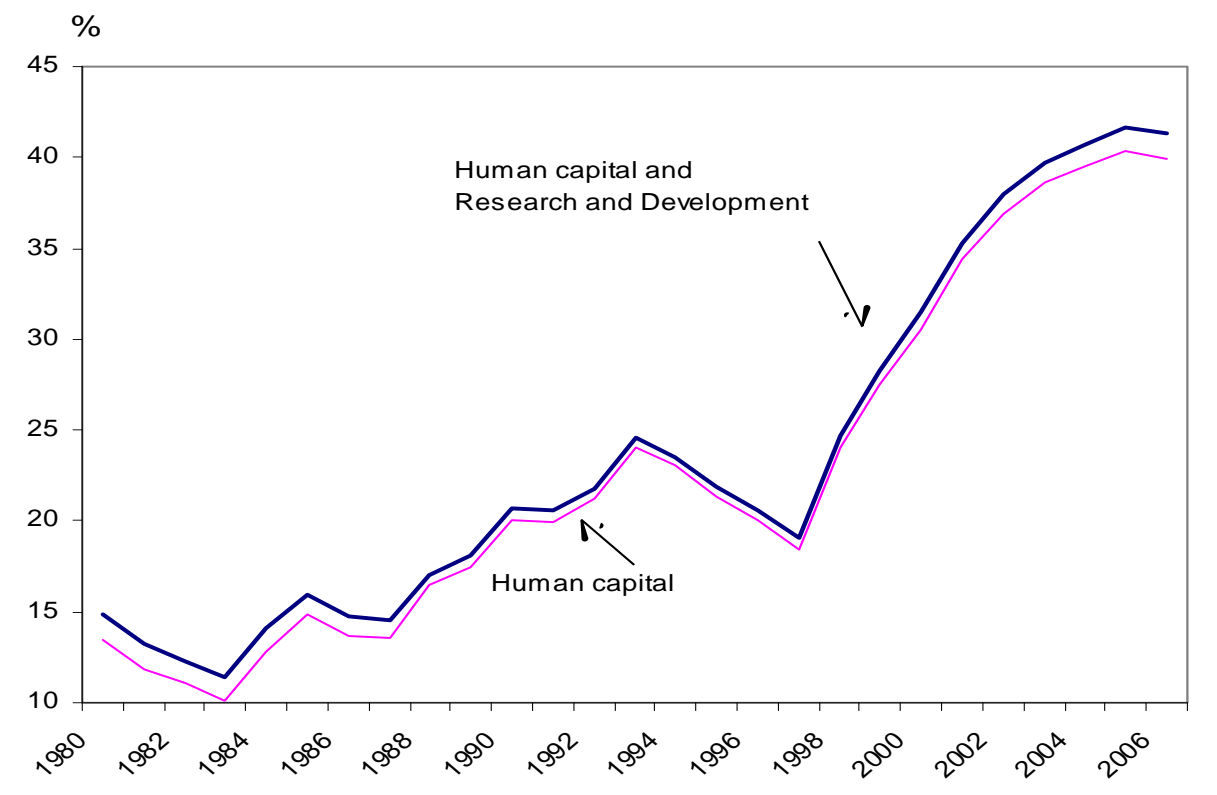

Figure 4: Human capital and R\&D (\%GDP): China 


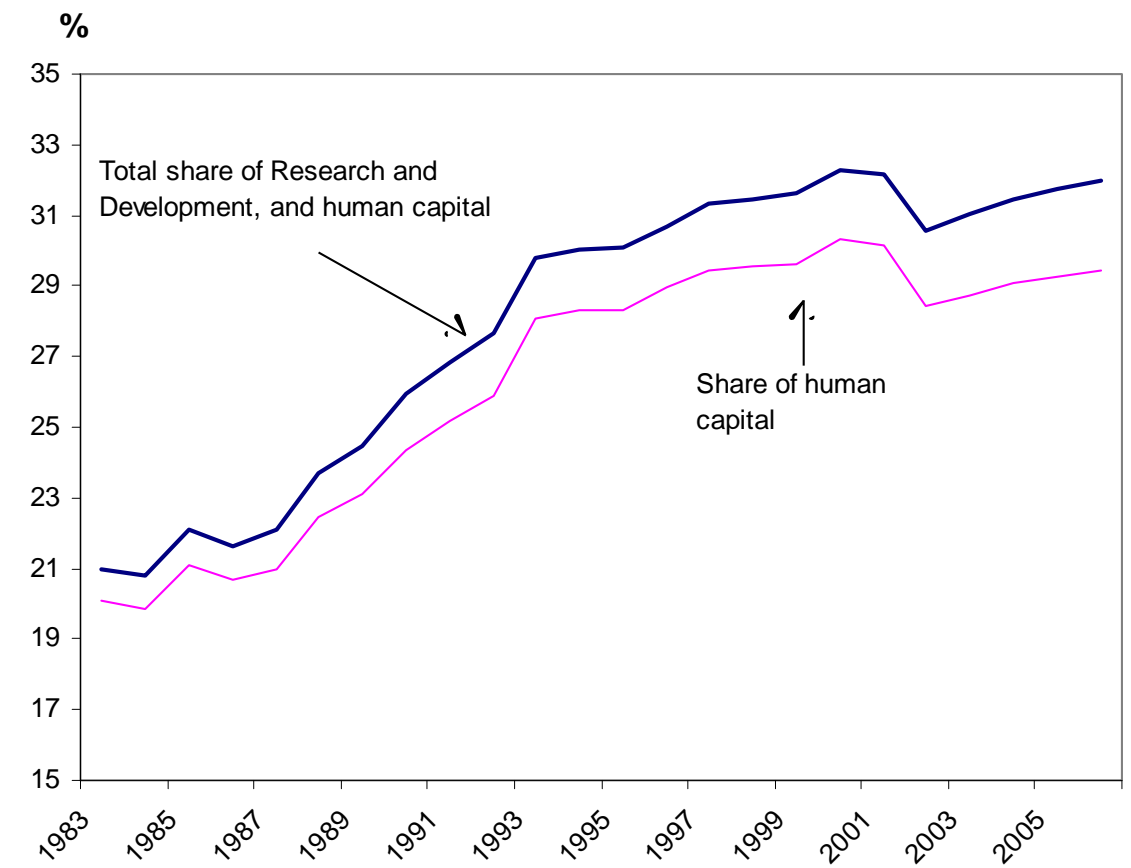

Figure 5: Human capital and R\&D (\%GDP): Taiwan

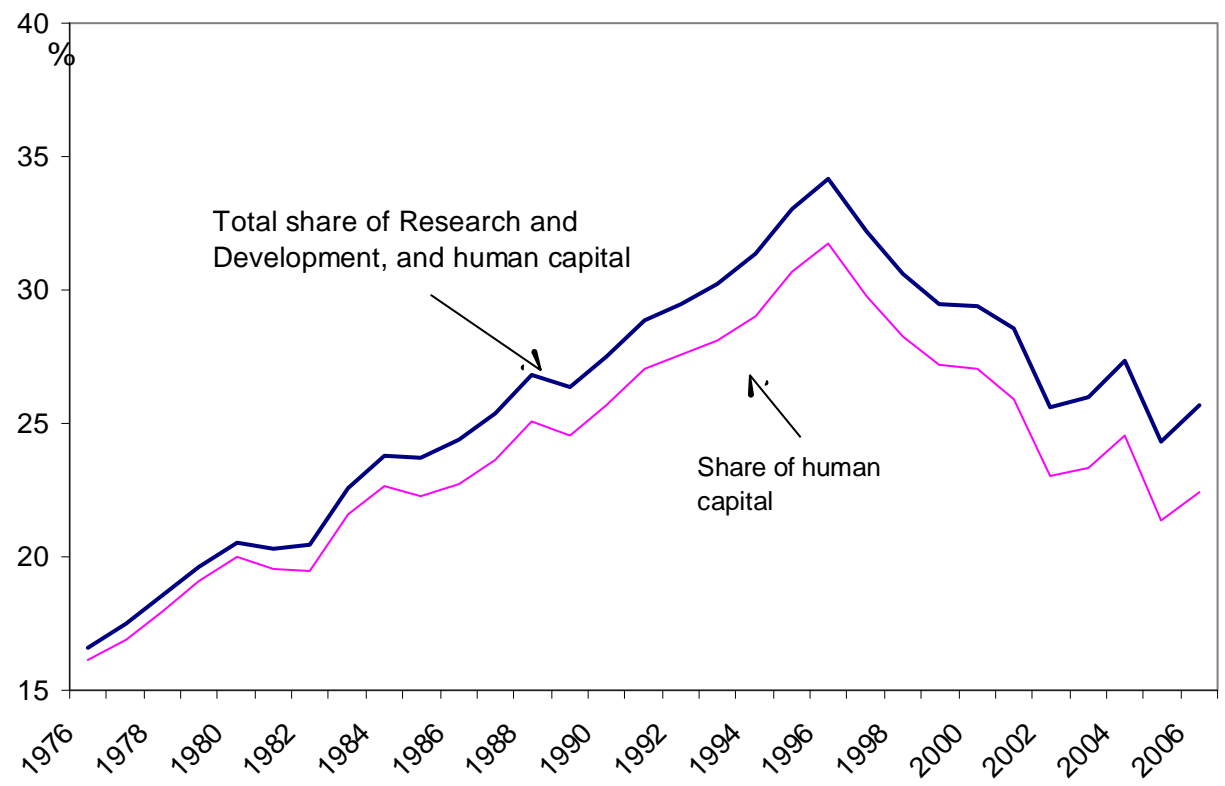

Figure 6: Human capital and R\&D (\%GDP): South Korea

\section{Conclusion}


At low economic level, a country would invest only in physical capital but at higher stage it would need to invest not only in physical capital but also in new technology and in high education.

Under some mild conditions on the quality of the production of new technology and on the supply of skilled workers, the share of the investment, in human capital, and in new technology and human capital, increases when the country becomes rich.

Thanks to new technology and human capital, the Total Factor Productivity increases and induces growth, the optimal path $\left(S_{t}^{*}\right)$ goes to $+\infty$. The economy grows unabated. The share $\theta_{t}^{*}+\mu_{t}^{*}$ of investment in new technology and human capital $\left(\theta_{t}^{*}+\mu_{t}^{*}\right)$ increases while the share in physical capital decreases. In concordance with Barro and Sala-i-Martin (2004), the share $\mu_{t}^{*}$ exceeds the share for physical and new technology capitals when $t$ goes to infinity. They converge to strictly positive values when time goes to infinity.

The empirical tests confirm the theoretical results. They support our prediction that when income is under a critical level there is no demand for investing in human capital. There exists a threshold for investing in human capital in the course of development.

Our predictions of the shares of human capital and of new technology, and of physical capital, are coherent with empirical data from the economies of China, Korea, and Taiwan.

\section{Appendix 1}

Proof of Proposition 1 .

Step 1Define

$$
B=\left\{S \geq 0: F\left(r_{e}, S\right)=x_{0} L_{d}^{* 1-\alpha_{d}}\right\}
$$

Lemma 1 B is a nonempty compact set. 
Proof: Bruno et al (2008).

As $F\left(r_{e}, S\right) \geq x_{0} L_{d}^{* 1-\alpha_{d}}$, if the optimal value for $\theta$ equals 0 then the one for $\mu$ is also 0 and $F\left(r_{e}, S\right)=x_{0} L_{d}^{* 1-\alpha_{d}}$.

Step 2 Lemma 2 shows that if $S$ is small, then the country does not invest in new technology and human capital. When $S$ is large, then it will invest in new technology.

Lemma 2 i) There exists $\underline{S}>0$ such that if $S \leq \underline{S}$ then $\theta=0$ and $\mu=0$.

ii) There exists $\bar{S}$ such that if $S>\bar{S}$ then $\theta>0$.

Proof: For any $S$, denote by $\theta(S)$ and $\mu(S)$ the corresponding optimal values for $\theta$ and $\mu$.

(i) Let $\underline{S}$ satisfies

$$
r_{e} \underline{S}^{\alpha_{e}} h(\underline{S})^{1-\alpha_{e}}=X
$$

Then for any $(\theta, \mu) \in \Delta$, for any $S \leq \underline{S}$,

$$
r_{e} \theta^{\alpha_{e}} S^{\alpha_{e}} h(\mu S)^{1-\alpha_{e}} \leq X
$$

and $(\theta(S), \mu(S))=(0,0)$.

(ii) Fix $\mu=0$ and $\theta \in(0,1)$. Then $\psi\left(r_{e}, \theta, 0, S\right) \rightarrow+\infty$ when $S \rightarrow+\infty$. Let $\bar{S}$ satisfy $\psi\left(r_{e}, \theta, 0, \bar{S}\right)>x_{0} L_{d}^{* 1-\alpha_{d}} . F\left(r_{e}, \bar{S}\right) \geq \psi\left(r_{e}, \theta, 0, \bar{S}\right)>x_{0} L_{d}^{* 1-\alpha_{d}}$, and $\theta(\bar{S})>0$. If not, then $\mu(\bar{S})=0$ and $F\left(r_{e}, \bar{S}\right)=x_{0} L_{d}^{* 1-\alpha_{d}}$.

Step 3 : Proof of Proposition 1

Define

$$
S^{c}=\max \{S \geq 0: S \in B\}
$$

As $S^{c} \geq \underline{S}>0$ and $B$ is compact, $0<S^{c}<+\infty$

For any $S \geq 0$ we have:

$$
F\left(r_{e}, S\right) \geq x_{0} L_{d}^{* 1-\alpha_{d}}
$$


If $S<S^{c}$ then for any $(\theta, \mu) \in \Delta$,

$$
\psi\left(r_{e}, \theta, \mu, S\right) \leq \psi\left(r_{e}, \theta, \mu, S^{c}\right)
$$

which implies

$$
F\left(r_{e}, S\right) \leq F\left(r_{e}, S^{c}\right)=x_{0} L_{d}^{* 1-\alpha_{d}}
$$

Thus,

$$
F\left(r_{e}, S\right)=x_{0} L_{d}^{* 1-\alpha_{d}}
$$

Let $S_{0}<S^{c}$. Assume that there exists two optimal values for $(\theta, \mu)$ which are $(0,0)$ and $\left(\theta_{0}, \mu_{0}\right)$ with $\theta_{0}>0$. We have $F\left(r_{e}, S_{0}\right)=x_{0} L_{d}^{* 1-\alpha_{d}}=\psi\left(r_{e}, \theta_{0}, \mu_{0}, S_{0}\right)$. We must have $r_{e} \theta_{0}^{\alpha_{e}} S_{0}^{\alpha_{e}} h\left(\mu_{0} S_{0}\right)^{1-\alpha_{e}}>X$ (if not, $\Phi\left(r_{e}, \theta_{0}, \mu_{0}, S_{0}\right)=x_{0}$ and $\left.\theta_{0}=0, \mu_{0}=0.\right)$

As $\theta_{0}>0$, we have $r_{e} \theta_{0}^{\alpha_{e}}\left(S^{c}\right)^{\alpha_{e}} h\left(\mu_{0} S_{0}\right)^{1-\alpha_{e}}>r_{e} \theta_{0}^{\alpha_{e}} S_{0}^{\alpha_{e}} h\left(\mu_{0} S_{0}\right)^{1-\alpha_{e}}>X$. Hence

$$
\begin{aligned}
x_{0} L_{d}^{* 1-\alpha_{d}}=F\left(r_{e}, S^{c}\right) & \geq \psi\left(r_{e}, \theta_{0}, \mu_{0}, S^{c}\right) \\
& >\psi\left(r_{e}, \theta_{0}, \mu_{0}, S_{0}\right)=x_{0} L_{d}^{* 1-\alpha_{d}}
\end{aligned}
$$

which is a contradiction.

Therefore, if $S>S^{c}$ then

$$
F\left(r_{e}, S\right)>x_{0} L_{d}^{* 1-\alpha_{d}}
$$

which implies $\theta(S)>0$.

\section{Proof of Proposition 2}

1. Take $S>S^{c}$. From the Proposition $1, \theta(S)>0$. Assume $\mu(S)=0$. For 
short, denote $\theta^{*}=\theta(S)$. Define

$$
F^{0}\left(r_{e}, S, \theta^{*}, 0\right)=\operatorname{Max}_{0 \leq \theta \leq 1} \psi\left(r_{e}, \theta, 0, S\right)=\Phi\left(r_{e} \theta^{* \alpha_{e}} S^{\alpha_{e}} h(0)^{1-\alpha_{e}}\right)\left(1-\theta^{*}\right)^{\alpha_{d}} L_{d}^{* 1-\alpha_{d}}
$$

and consider a feasible couple $(\theta, \mu)$ in $\Delta$ which satisfies $\theta^{*}=\theta+\mu$. Denote

$$
F^{1}\left(r_{e}, S, \theta, \mu\right)=\Phi\left(r_{e} \theta^{\alpha_{e}} S^{\alpha_{e}} h(\mu S)^{1-\alpha_{e}}\right)\left(1-\theta^{*}\right)^{\alpha_{d}} L_{d}^{* 1-\alpha_{d}}
$$

We then have:

$$
\begin{aligned}
& \frac{F^{1}\left(r_{e}, S, \theta, \mu\right)-F^{0}\left(r_{e}, S, \theta^{*}, 0\right)}{\left(1-\theta^{*}\right)^{\alpha_{d}} L_{d}^{* 1-\alpha_{d}}} \\
= & \Phi\left(r_{e} \theta^{\alpha_{e}} S^{\alpha_{e}} h(\mu S)^{1-\alpha_{e}}\right)-\Phi\left(r_{e} \theta^{* \alpha_{e}} S^{\alpha_{e}} h(0)^{1-\alpha_{e}}\right) \\
= & r_{e} S^{\alpha_{e}}\left(\theta^{\alpha_{e}} h(\mu S)^{1-\alpha_{e}}-\theta^{* \alpha_{e}} h(\mu S)^{1-\alpha_{e}}+\theta^{* \alpha_{e}} h(\mu S)^{1-\alpha_{e}}-\theta^{* \alpha_{e}} h(0)^{1-\alpha_{e}}\right)
\end{aligned}
$$

By the concavity of $h(x)$ and $f(x)=x^{\alpha_{e}}$, we obtain

$$
\begin{aligned}
& F^{1}\left(r_{e}, S, \theta, \mu\right)-F^{0}\left(r_{e}, S, \theta^{*}, 0\right) \geq \\
& r_{e} S^{\alpha_{e}} \mu h(\mu S)^{-\alpha_{e}}\left(-\alpha_{e} h(\mu S)\left(\theta^{*}-\mu\right)^{\alpha_{e}-1}+S\left(1-\alpha_{e}\right) \theta^{* \alpha_{e}} h^{\prime}(\mu S)\right)
\end{aligned}
$$

When $\mu \rightarrow 0, h^{\prime}(\mu S) \rightarrow+\infty$. The expression in the big parentheses converges to $+\infty$, which is contradicting with the optimality of $\theta^{*}$.

2. Assume that $\mu(S)=0$ for any $S \in\left\{S^{1}, S^{2}, \ldots, S^{n}, \ldots\right\}$ where the infinite sequence $\left\{S^{n}\right\}_{n}$ is increasing, goes to $+\infty$ and satisfies $S^{1}>S^{c}$. For short, denote $\theta=\theta(S)$. Then we have the following first order condition:

$$
\frac{a r_{e} \theta^{\alpha_{e}-1} S^{\alpha_{e}} h(0)^{1-\alpha_{e}} \alpha_{e}}{x_{0}+a\left(r_{e} \theta^{\alpha_{e}} S^{\alpha_{e}} h(0)^{1-\alpha_{e}}-X\right)}=\frac{\alpha_{d}}{1-\theta}
$$

and

$$
\frac{a r_{e} \theta^{\alpha_{e}} S^{\alpha_{e}+1} h^{\prime}(0) h(0)^{-\alpha_{e}}\left(1-\alpha_{e}\right)}{x_{0}+a\left(r_{e} \theta^{\alpha_{e}} S^{\alpha_{e}} h(0)^{1-\alpha_{e}}-X\right)} \leq \frac{\alpha_{d}}{1-\theta} .
$$


Eq. (44) implies

$$
\frac{a r_{e} \theta^{\alpha_{e}-1} h(0)^{1-\alpha_{e}} \alpha_{e}}{\frac{x_{0}}{S^{\alpha_{e}}}+a\left(r_{e} \theta^{\alpha_{e}} h(0)^{1-\alpha_{e}}\right)} \leq \frac{\alpha_{d}}{1-\theta} .
$$

If $\theta \rightarrow 0$ when $S \rightarrow+\infty$, then the LHS of inequality (46) converges to infinity while the RHS converges to $\alpha_{d}$ : this is a contradiction. Thus $\theta$ will be bounded away from 0 when $S$ goes to infinity.

Combining Eq. (44) and inequality (45) we get:

$$
h^{\prime}(0)\left(1-\alpha_{e}\right) S \leq h_{0} \alpha_{e} \theta^{-1}
$$

When $S \rightarrow+\infty$, we have a contradiction because the LHS of Eq.(47) goes to infinity while the RHS is upper bounded. There exists $S_{M}$ such that for any $S \geq S_{M}, \mu(S)>0$.

3. Let $S>S^{c}$. For short, we denote $\mu$ and $\theta$ instead of $\mu(S)$ and $\theta(S)$. If $\mu>0$ then we have the first order condition:

$$
\frac{a r_{e} \theta^{\alpha_{e}-1} S^{\alpha_{e}} h(\mu S)^{1-\alpha_{e}} \alpha_{e}}{x_{0}+a\left(r_{e} \theta^{\alpha_{e}} S^{\alpha_{e}} h(\mu S)^{1-\alpha_{e}}-X\right)}=\frac{\alpha_{d}}{1-\theta-\mu}
$$

and

$$
\frac{a r_{e} \theta^{\alpha_{e}} S^{\alpha_{e}+1} h^{\prime}(\mu S) h(\mu S)^{-\alpha_{e}}\left(1-\alpha_{e}\right)}{x_{0}+a\left(r_{e} \theta^{\alpha_{e}} S^{\alpha_{e}} h(\mu S)^{1-\alpha_{e}}-X\right)}=\frac{\alpha_{d}}{1-\theta-\mu} .
$$

Let $\theta^{c}$ and $S^{c}$ satisfy:

$$
\frac{a r_{e}\left(\theta^{c}\right)^{\alpha_{e}-1}\left(S^{c}\right)^{\alpha_{e}} h(0)^{1-\alpha_{e}} \alpha_{e}}{x_{0}+a\left(r_{e}\left(\theta^{c}\right)^{\alpha_{e}}\left(S^{c}\right)^{\alpha_{e}} h(0)^{1-\alpha_{e}}-X\right)}=\frac{\alpha_{d}}{1-\theta^{c}}
$$

and

$$
\left(x_{0}+a\left(r_{e}\left(\theta^{c}\right)^{\alpha_{e}}\left(S^{c}\right)^{\alpha_{e}} h(0)^{1-\alpha_{e}}-X\right)\right)\left(1-\theta^{c}\right)^{\alpha_{d}}=x_{0}
$$

Eq. (50) is the first order condition with respect to $\theta$, while Eq. (51) states that $\psi\left(r_{e}, \theta^{c}, 0, S^{c}\right)=x_{0} L_{d}^{* 1-\alpha_{d}}$. If $h^{\prime}(0)<\alpha=h(0) \frac{1}{\theta^{c} S^{c}} \frac{\alpha_{e}}{1-\alpha_{e}}, \theta^{c}>0$ as defined in 
Bruno et al. (2008), then:

$$
\frac{a_{e}\left(\theta^{c}\right)^{\alpha_{e}}\left(S^{c}\right)^{\alpha_{e}+1} h^{\prime}(0) h(0)^{-\alpha_{e}}\left(1-\alpha_{e}\right)}{x_{0}+a\left(r_{e}\left(\theta^{c}\right)^{\alpha_{e}}\left(S^{c}\right)^{\alpha_{e}} h(0)^{1-\alpha_{e}}-X\right)}<\frac{\alpha_{d}}{1-\theta^{c}} .
$$

Eq. (50), (51), and (52) give the values of $S^{c}$ and $\theta\left(S^{c}\right)=\theta^{c}$ and $\mu\left(S^{c}\right)=\mu^{c}=$ 0. When $S>S^{c}$ and close to $S^{c}$, Eq. (50) and inequality (52) still hold true. That means $\mu(S)=0$ for any $S$ close to $S^{c}$.

\section{Proof of Proposition 3}

Step 1

Lemma 3 Assume $h^{\prime}(0)<+\infty$. Let $S^{1}>S^{c}$. If $\mu\left(S^{1}\right)=0$, then for $S^{2}<S^{1}$, we also have $\mu\left(S^{2}\right)=0$.

Proof: If $S^{2} \leq S^{c}$ then $\mu\left(S^{2}\right)=0$ because $\theta\left(S^{2}\right)=0$ (see Proposition 1). For short, we write $\theta_{1}=\theta\left(S^{1}\right), \theta_{2}=\theta\left(S^{2}\right), \mu_{1}=\mu\left(S^{1}\right), \mu_{2}=\mu\left(S^{2}\right)$.

$\left(\theta_{1}, S^{1}\right)$ satisfy Eq. (44) and (45), or equivalently Eq. (44) and (47). Eq. (44) is written as

$$
h_{0}^{1-\alpha_{e}} \operatorname{ar}_{e}\left(\alpha_{e} \theta_{1}^{\alpha_{e}-1}-\left(\alpha_{e}+\alpha_{d}\right) \theta_{1}^{\alpha_{e}}\right)=\frac{\alpha_{d}\left(x_{0}-a X\right)}{S^{\alpha^{\alpha_{e}}}} .
$$

If $x_{0}-a X=0$, then $\theta_{1}=\frac{\alpha_{e}}{\alpha_{e}+\alpha_{d}}$. Take $\theta_{2}=\theta_{1}$. If $S^{2}<S^{1}$ then $\left(\theta_{2}, S^{2}\right)$ satisfy Eq. (44) and (47). That means they satisfy the first order condition. with $\mu_{2}=0$.

The LHS of Eq. (53) is a decreasing function in $\theta_{1}$. Hence $\theta_{1}$ is determined uniquely.

When $x_{0}>a X$, if $\left(\theta_{2}, S^{2}\right)$ satisfy Eq. (53), with $S^{2}<S^{1}$, then $\theta_{2}<\theta_{1}$. In this case, $\left(\theta_{2}, S^{2}\right)$ also satisfy Eq. (47), and we have $\mu_{2}=0$.

When $x_{0}<a X$, write Eq. (53) as:

$$
h_{0}^{1-\alpha_{e}} \operatorname{ar}_{e}\left(\alpha_{e} \theta_{1}^{-1}-\left(\alpha_{e}+\alpha_{d}\right)\right)=\frac{\alpha_{d}\left(x_{0}-a X\right)}{\left(\theta_{1} S^{1}\right)^{\alpha_{e}}} .
$$


If $\left(\theta_{2}, S^{2}\right)$ satisfy Eq. (53), with $S^{2}<S^{1}$, then $\theta_{2}>\theta_{1}$. As $x_{0}<a X$, from Eq. (54), we have $\theta_{2} S^{2}<\theta_{1} S^{1}$. Again $\left(\theta_{2}, S^{2}\right)$ satisfy Eq. (53) and (47). That implies $\mu_{2}=0$.

Step 2

Let

$$
\widetilde{S}=\max \left\{S_{m}: S_{m} \geq S^{c}, \text { and } S \leq S_{m} \Rightarrow \mu(S)=0\right\}
$$

and

$$
\widetilde{\widetilde{S}}=\inf \left\{S_{M}: S_{M}>S^{c}, \text { and } S>S_{M} \Rightarrow \mu(S)>0\right\}
$$

From Proposition 2, the sets $\left\{S_{m}: S_{m}>S^{c}\right.$, and $\left.S \leq S_{m} \Rightarrow \mu(S)=0\right\}$ and $\left\{S_{M}: S_{M}>S^{c}\right.$, and $\left.S>S_{M} \Rightarrow \mu(S)>0\right\}$ are not empty. From Step 1, we

have $\widetilde{\widetilde{S}} \geq \widetilde{S}$. If $\widetilde{\widetilde{S}}>\widetilde{S}$, then take $S \in(\widetilde{S}, \widetilde{\widetilde{S}})$. From the definitions of $\widetilde{S}$ and $\widetilde{\widetilde{S}}$, there exist $S_{1}<S$, and $S_{2}>S$ such that $\mu\left(S_{1}\right)>0$ and $\mu\left(S_{2}\right)=0$. But that contradicts Step 1. Hence $\widetilde{\widetilde{S}}=\widetilde{S}$. Putting $\widehat{S}=\widetilde{\widetilde{S}}=\widetilde{S}$ leads to the proof.

\section{Proof of Proposition 4}

From Proposition 3, we have $\mu^{c}=0$. In this case, $\theta^{c}$ and $S^{c}$ satisfy Eq. (48) and, since $S^{c} \in B$, we also have $F\left(r_{e}, S^{c}\right)=\psi\left(r_{e}, \theta^{c}, 0, S^{c}\right)=x_{0} L_{d}^{* 1-\alpha_{d}}$.

Explicitly, we have

$$
\frac{a r_{e}\left(\theta^{c}\right)^{\alpha_{e}-1}\left(S^{c}\right)^{\alpha_{e}} h_{0}^{1-\alpha_{e}} \alpha_{e}}{x_{0}+a\left(r_{e}\left(\theta^{c}\right)^{\alpha_{e}}\left(S^{c}\right)^{\alpha_{e}} h_{0}^{1-\alpha_{e}}-X\right)}=\frac{\alpha_{d}}{1-\theta^{c}}
$$

and

$$
\left(x_{0}+a\left(r_{e}\left(\theta^{c}\right)^{\alpha_{e}}\left(S^{c}\right)^{\alpha_{e}} h_{0}^{1-\alpha_{e}}-X\right)\right)\left(1-\theta^{c}\right)^{\alpha_{d}}=x_{0}
$$

Computations show that $\theta^{c}$ satisfies:

$$
\alpha_{e}\left(1-\frac{x_{0}-a X}{x_{0}}(1-\theta)^{\alpha_{d}+1}\right)=\theta\left(\alpha_{d}+\alpha_{e}\right)
$$

If $x_{0}>a X$, the LHS is a strictly concave function which increases from $\frac{\alpha_{e} a X}{x_{0}}$ when $\theta=0$ to $\alpha_{e}$ when $\theta=1$. The RHS is linearly increasing, equal to 0 at 
the origin and to $\alpha_{d}+\alpha_{e}$ when $\theta=1$. Then, there exists a unique solution $\theta^{c} \in(0,1)$.

If $x_{0}<a X$, the LHS is a strictly convex function which decreases from $\frac{\alpha_{e} a X}{x_{0}}$ when $\theta=0$ to $\alpha_{e}$ when $\theta=1$. The RHS is linear increasing, equal to 0 at the origin and to $\alpha_{d}+\alpha_{e}$ when $\theta=1$. Then, there exists a unique solution $\theta^{c} \in(0,1)$.

If $x_{0}=a X$, then $\theta^{c}=\frac{\alpha_{e}}{\alpha_{e}+\alpha_{d}}$.

In any case, $\theta^{c}$ does not depend on $r_{e} . \theta^{c}$ is positively related to $a$ if $x_{0} \neq$ $a X$. With a higher value of the spill-over indicator $a$ (better social capital and institutional capital), the economy not only invests in new technology earlier but also invests more initially.

Eq. (58) gives:

$$
\operatorname{ar}_{e}\left(S^{c}\right)^{\alpha_{e}}=\left(x_{0}\left(\frac{1}{\left(1-\theta^{c}\right)^{\alpha_{d}}}-1\right)+a X\right) \frac{1}{\left(\theta^{c}\right)^{\alpha_{e}} h_{0}^{1-\alpha_{e}}}
$$

$S^{c}$ is a decreasing function in $a$ and $r_{e}$.

Proof of Proposition 7 Let $S^{s}$ be defined by

$$
\alpha_{d}\left(S^{s}\right)^{\alpha_{d}-1} x_{0} L_{d}^{* 1-\alpha_{d}}=\frac{1}{\beta}
$$

If $S_{0}>\widehat{S}(\widehat{S}$ is defined in Proposition 3$)$ then $\theta_{t}^{*}>0, \mu_{t}^{*}>0$ for every $t$. If $S_{0}>S^{c}$ then $\theta_{t}^{*}>0$ for every $t$. If $S_{t}^{*}$ converges to infinity, then there exists $T_{2}$ where $S_{T_{2}}^{*}>\widehat{S}$ and $\theta_{t}^{*}>0, \mu_{t}^{*}>0$ for every $t \geq T_{2}$.

Consider the case where $0<S_{0}<S^{c}$. Obviously, $\theta_{0}^{*}=0$. If $a$ or $r_{e}$ are large then $S^{c}<S^{s}$. If for any $t, \theta_{t}^{*}=0$, also $K_{e, t}^{*}=0 \forall t$, and the optimal path $\left(S_{t}^{*}\right)_{t}$ converges to $S^{s}$ (Le Van and Dana 2003). But, $S^{c}<S^{s}$, hence the optimal path $\left(S_{t}^{*}\right)_{t}$ is non decreasing and exceeds $S^{c}$ after some date $T_{1}$ and $\theta_{t}^{*}>0$ when $t \geq T_{1}$.

If the optimal path $\left(S_{t}^{*}\right)_{t}$ goes to infinity, then after some date $T_{2}, S_{t}^{*}>\widehat{S}$ for 
any $t>T_{2}$ and $\theta_{t}^{*}>0, \mu_{t}^{*}>0$.

It remains to prove that the optimal path goes to infinity if $a$ or $r_{e}$ are large enough.

The utility function $u$ satisfies the Inada condition $u^{\prime}(0)=+\infty$, and the Euler equation:

$$
u^{\prime}\left(c_{t}^{*}\right)=\beta u^{\prime}\left(c_{t+1}^{*}\right) H_{s}^{\prime}\left(r_{e}, S_{t+1}^{*}\right)
$$

If $S_{t}^{*} \rightarrow \bar{S}<\infty$, then $c_{t}^{*} \rightarrow \bar{c}>0$. From Euler equation, we get

$$
H_{s}^{\prime}\left(r_{e}, \bar{S}\right)=\frac{1}{\beta}
$$

We show that $H_{s}^{\prime}\left(r_{e}, S\right)>\frac{1}{\beta}$ for any $S>S^{c}$. We have

$$
\begin{aligned}
H_{s}^{\prime}\left(r_{e}, S\right) & =F_{s}^{\prime}\left(r_{e}, S\right) S^{\alpha_{d}}+\alpha_{d} F\left(r_{e}, S\right) S^{\alpha_{d}-1} \\
& \geq F_{s}^{\prime}\left(r_{e}, S\right) S^{\alpha_{d}}
\end{aligned}
$$

From the envelope theorem we get:

$$
\begin{aligned}
& F_{s}^{\prime}\left(r_{e}, S\right) S^{\alpha_{d}}= \\
& \quad\left(a_{e} \theta^{* \alpha_{e}}\left(h\left(\mu^{*} S\right)\right)^{-\alpha_{e}}\left(\alpha_{e} h\left(\mu^{*} S\right)+\left(1-\alpha_{e}\right) \mu^{*} S h^{\prime}\left(\mu^{*} S\right)\right) S^{\alpha_{d}+\alpha_{e}-1}\right) \\
& \quad \times L_{d}^{* 1-\alpha_{d}}\left(1-\theta^{*}-\mu^{*}\right)^{\alpha_{d}}
\end{aligned}
$$

When $a r_{e}$ is large, from Proposition 5, we have $\theta^{*} \geq \underline{\theta}=\min \left\{\theta^{c}, \theta_{\infty}\right\}$ and $\theta^{*}+\mu^{*} \leq \bar{\zeta}=\max \left\{\theta^{c}, \theta_{\infty}+\mu_{\infty}\right\}$. Then:

$$
\begin{aligned}
H_{s}^{\prime}\left(r_{e}, S\right) & \geq L_{d}^{* 1-\alpha_{d}}\left(1-\theta^{*}-\mu^{*}\right)^{\alpha_{d}} a r_{e} \theta^{* \alpha_{e}}\left(h^{*}(\mu S)\right)^{1-\alpha_{e}} \alpha_{e} S^{\alpha_{d}+\alpha_{e}-1} \\
& \geq L_{d}^{* 1-\alpha_{d}}(1-\bar{\zeta})^{\alpha_{d}} a r_{e} \underline{\theta}^{\alpha_{e}}\left(h^{*}(0)\right)^{1-\alpha_{e}} \alpha_{e}\left(S^{c}\right)^{\alpha_{d}+\alpha_{e}-1}
\end{aligned}
$$

because $h(x) \geq h(0)$ and $\alpha_{d}+\alpha_{e}-1 \geq 0$. 
If $\alpha_{d}+\alpha_{e}=1$, then

$$
H_{s}^{\prime}\left(r_{e}, S\right) \geq L_{d}^{* 1-\alpha_{d}}(1-\bar{\zeta})^{\alpha_{d}} a r_{e} \underline{\theta}^{\alpha_{e}}\left(h^{*}(0)\right)^{1-\alpha_{e}} \alpha_{e}
$$

and when $a r_{e}$ becomes very large, the RHS of inequality (67) will be larger than $\frac{1}{\beta}$.

Assume $\alpha_{d}+\alpha_{e}>1$. From Eq. (60), the quantity $\operatorname{ar}_{e}\left(S^{c}\right)^{\alpha_{e}}$ equals

$$
\gamma=\left(x_{0}\left(\frac{1}{\left(1-\theta^{c}\right)^{\alpha_{d}}}-1\right)+a X\right) \frac{1}{\left(\theta^{c}\right)^{\alpha_{e}} h_{0}^{1-\alpha_{e}}}
$$

and

$$
S^{c}=\left(\frac{\gamma}{a r_{e}}\right)^{\frac{1}{\alpha_{e}}}
$$

We have

$$
H_{s}^{\prime}\left(r_{e}, S\right) \geq L_{d}^{* 1-\alpha_{d}}(1-\bar{\zeta})^{\alpha_{d}} \underline{\theta}^{\alpha_{e}}\left(h^{*}(0)\right)^{1-\alpha_{e}} \alpha_{e} \gamma\left(\frac{\gamma}{a r_{e}}\right)^{\frac{\alpha_{d}-1}{\alpha_{e}}}
$$

Because $\alpha_{d}-1<0$, when ar $_{e}$ is large, $H_{s}^{\prime}\left(r_{e}, S\right)>\frac{1}{\beta}$. 


\section{Appendix 2: Data}

Table 2: Inputs and Technical Progress

Contributions (in percent) of the Sources of Growth

\begin{tabular}{|c|c|c|c|c|c|}
\hline & $\begin{array}{l}\text { Sample } \\
\text { period }\end{array}$ & $\begin{array}{c}\text { Physical } \\
\text { capital }\end{array}$ & Labor & $\begin{array}{l}\text { Human } \\
\text { capital }\end{array}$ & $\begin{array}{l}\text { Technical } \\
\text { progress }\end{array}$ \\
\hline \multicolumn{6}{|c|}{ (1) Before 1973} \\
\hline Hong Kong & $1966-73$ & $68.37(9.67)$ & $28.50(3.10)$ & $3.13(5.57)$ & 0.00 \\
\hline S. Korea & $1960-73$ & $72.60(11.58)$ & $21.87(4.14)$ & $5.53(7.70)$ & 0.00 \\
\hline Singapore & $1964-73$ & $55.59(12.73)$ & $40.18(7.56)$ & $4.22(9.17)$ & 0.00 \\
\hline Taiwan & $1953-73$ & $80.63(13.21)$ & $15.45(2.63)$ & $3.91(6.73)$ & 0.00 \\
\hline Indonesia & $1970-73$ & $73.09(11.09)$ & $9.37(2.15)$ & $17.54(19.50)$ & 0.00 \\
\hline Malaysia & $1970-73$ & $59.97(9.56)$ & $29.99(4.32)$ & $10.05(12.64)$ & 0.00 \\
\hline Philippines & $1970-73$ & $39.79(5.12)$ & $49.97(7.36)$ & $10.24(11.51)$ & 0.00 \\
\hline Thailand & $1970-73$ & $82.11(10.96)$ & $7.67(0.57)$ & $10.22(11.44)$ & 0.00 \\
\hline China & $1965-73$ & $85.29(13.51)$ & $10.36(3.19)$ & $4.35(7.01)$ & 0.00 \\
\hline Japan & $1957-73$ & $55.01(11.43)$ & $4.85(0.82)$ & $1.06(2.87)$ & 39.09 \\
\hline$* \mathrm{G}-5$ & $1957-73$ & $41.50(4.62)$ & $6.00(4.24)$ & $1.43(1.70)$ & 51.07 \\
\hline \multicolumn{6}{|l|}{ (2) 1974-85 } \\
\hline Hong Kong & $1974-85$ & $64.31(9.58)$ & $32.73(3.40)$ & $2.96(5.67)$ & 0.00 \\
\hline South Korea & $1974-85$ & $78.08(13.28)$ & $18.10(2.83)$ & $3.81(6.41)$ & 0.00 \\
\hline Singapore & $1974-85$ & $64.68(9.94)$ & $31.72(3.42)$ & $3.60(5.48)$ & 0.00 \\
\hline Taiwan & $1974-85$ & $78.91(11.89)$ & $18.12(2.23)$ & $2.97(4.98)$ & 0.00 \\
\hline Indonesia & $1974-85$ & $77.69(12.22)$ & $13.55(2.65)$ & $8.76(10.20)$ & 0.00 \\
\hline Malaysia & $1974-85$ & $61.39(10.76)$ & $33.61(4.94)$ & $5.00(8.15)$ & 0.00 \\
\hline Philippines & $1974-85$ & $62.59(7.29)$ & $29.28(3.53)$ & $8.13(8.07)$ & 0.00 \\
\hline Thailand & $1974-85$ & $67.53(8.69)$ & $25.02(3.55)$ & $7.46(8.96)$ & 0.00 \\
\hline China & $1974-85$ & $80.46(9.44)$ & $14.64(2.53)$ & $4.09(6.37)$ & 0.00 \\
\hline Japan & $1974-85$ & $40.65(6.73)$ & $10.22(0.93)$ & $0.96(1.69)$ & 48.17 \\
\hline${ }^{*} \mathrm{G}-5$ & $1974-85$ & $36.29(2.65)$ & $-14.55(-0.42)$ & $2.53(1.90)$ & 75.73 \\
\hline
\end{tabular}

In parentheses the average annual rates of growth of each inputs.

${ }^{*}$ G-5: France, West Germany, Japan UK, and US. 
Table 2 (cont.): Inputs and Technical Progress Contributions (in percent) of the Sources of Growth

\begin{tabular}{cccccc}
\hline & Sample & Physical & Labor & Human & Technical \\
& period & capital & & capital & progress \\
\hline (3) After 1986 & & & & & \\
Hong Kong & $1986-95$ & $41.81(7.56)$ & $6.46(0.53)$ & $1.58(3.10)$ & 50.14 \\
South Korea & $1986-95$ & $44.54(11.90)$ & $14.98(2.76)$ & $1.75(4.15)$ & 38.73 \\
Singapore & $1986-95$ & $37.01(8.50)$ & $31.30(4.32)$ & $1.52(3.38)$ & 30.17 \\
Taiwan & $1986-95$ & $43.00(9.01)$ & $10.46(1.34)$ & $1.38(3.13)$ & 45.16 \\
Indonesia & $1986-94$ & $62.79(8.88)$ & $15.91(2.31)$ & $5.69(6.94)$ & 15.61 \\
Malaysia & $1986-95$ & $42.87(8.53)$ & $33.41(4.83)$ & $3.25(6.15)$ & 20.47 \\
Philippines & $1986-95$ & $52.18(3.77)$ & $41.63(2.96)$ & $6.23(5.09)$ & -0.03 \\
Thailand & $1986-94$ & $51.01(11.27)$ & $13.32(2.72)$ & $2.36(5.25)$ & 33.31 \\
China & $1986-95$ & $86.39(12.54)$ & $10.34(1.92)$ & $3.27(4.54)$ & 0.00 \\
Japan & $1986-94$ & $38.21(4.86)$ & $2.47(0.11)$ & $1.17(1.44)$ & 58.14 \\
$*$ G-5 & $86-94$ & $27.14(2.70)$ & $13.83(5.37)$ & $1.58(1.36)$ & 57.45 \\
\hline
\end{tabular}

In parentheses, the average annual rates of growth of each inputs.

*G-5: France, West Germany, Japan, UK and US

Source: Lau and Park (2003) 


\section{Table 3: Countries in the Sample of Human Capital}

\begin{tabular}{|c|c|c|c|}
\hline Economies & Range & Economies & Range \\
\hline Algeria & $1950-2000$ & Malaysia & $1960-2000$ \\
\hline Argentina & $1950,1960-2000$ & Mali & $1960-2000$ \\
\hline Bangladesh & $1960-2000$ & Malta & $1950,1960-2000$ \\
\hline Barbados & $1960-2000$ & Mauritius & $1950,1960-2000$ \\
\hline Benin & $1960-2000$ & Mexico & $1950,1960-2000$ \\
\hline Bolivia & $1960-2000$ & Mozambique & $1960-2000$ \\
\hline Botswana & $1960-2000$ & Nepal & $1960-2000$ \\
\hline Brazil & $1960-2000$ & Nicaragua & $1950,1960-2000$ \\
\hline Cameroon & $1960-2000$ & Niger & $1960-2000$ \\
\hline Central African Republic & $1960-2000$ & Pakistan & $1960-2000$ \\
\hline Chile & $1950,1960-2000$ & Panama & $1950,1960-2000$ \\
\hline China & $1960-2000$ & Paraguay & $1950,1960-2000$ \\
\hline Colombia & $1950,1960-2000$ & Peru & $1960-2000$ \\
\hline Congo, Dem. Rep. & $1955-2000$ & Philippines & $1950-2000$ \\
\hline Congo, Republic of & $1960-2000$ & Poland & $1960-2000$ \\
\hline Costa Rica & $1950,1960-2000$ & Romania & $1950,1960-2000$ \\
\hline Cuba & $1955-2000$ & Rwanda & $1960-2000$ \\
\hline Cyprus & $1960-2000$ & Senegal & $1960-2000$ \\
\hline Dominican Republic & $1960-2000$ & Sierra Leone & $1960-2000$ \\
\hline Ecuador & $1950,1960-2000$ & Singapore & $1960-2000$ \\
\hline Egypt & $1960-2000$ & South Africa & $1960-2000$ \\
\hline El Salvador & $1950,1960-2000$ & Sri Lanka & $1960-2000$ \\
\hline Gambia, The & $1960-2000$ & Sudan & $1955-2000$ \\
\hline Ghana & $1960-2000$ & Swaziland & $1960-2000$ \\
\hline Guatemala & $1950,1960-2000$ & Syria & $1960-2000$ \\
\hline Haiti & $1950,1960-2000$ & Taiwan & $1960-2000$ \\
\hline Honduras & $1960-2000$ & Thailand & $1960-2000$ \\
\hline Hungary & $1960-2000$ & Togo & $1960-2000$ \\
\hline India & $1960-2000$ & Trinidad \&Tobago & $1960-2000$ \\
\hline Indonesia & $1960-2000$ & Tunisia & $1960-2000$ \\
\hline Jamaica & $1960-2000$ & Uganda & $1960-2000$ \\
\hline Jordan & $1960-2000$ & Uruguay & $1960-2000$ \\
\hline Kenya & $1960-2000$ & Venezuela & $1950,1960-2000$ \\
\hline Korea, Republic of & $1955-2000$ & Zambia & $1960-2000$ \\
\hline Lesotho & $1960-2000$ & Zimbabwe & $1960-2000$ \\
\hline Malawi & $1960-2000$ & & \\
\hline
\end{tabular}

Source: Barro and Lee (2000)

Data are calculated every 5 years and some data for 1955 are missing. 


\section{References}

Azariadis, C. and A. Drazen (1990). Threshold externalities in economic Development. Quarterly Journal of Economics, 2(105): 501-526

Barro, R. (1997). Determinants of Economic Growth: A Cross-countries Empirical Study. Cambridge: MIT Press.

Barro, R. J. and J. W. Lee (2000). International Data on Educational Attainment: Updates and Implications. Working Paper 42. Center for International Development (CID): Havard University.

Barro, R. and X. Sala-i-Martin. (2004) Economic Growth (2nd Edition). New York: McGraw Hill.

Baumol, W. J. (1986). Productivity Growth, Convergence, and Welfare: What the long-run data show. American Economic Review, (5)76: 1072-1085.

Baumol, W. J., S. A. B. Blackman and E. N. Wofff (1989). Productivity and American Leadership: The Long View. Cambridge Mass and London: MIT Press.

Bruno, O., C. Le Van, and B. Masquin (2009). When does a developing country use new technologies. Economic Theory, (2)40: 275-300.

Carsey, B. M. and X. Sala-i-Martin (1995). A Labor-Income-Based Measure of the Value of Human Capital: An Application to the United States. Working paper, 5018. National Bureau of Economic Research.

CEIC database: http://www.ceicdata.com/

Collins, S. M., B. P. Bosworth and D. Rodrik (1996). Economic Growth in East Asia: Accumulation versus Assimilation. Brookings Papers on Economic Activity, (2)1996: 135-203.

Dowrick, S. and D. T. Nguyen (1989). OECD Comparative Economic Growth 1950-85. American Economic Review, (5)79: 1010-1030. 
Eaton, J. and S. Kortum, (2001). Trade in Capital Goods. Working paper, 8070. National Bureau of Economic Research.

Galor, O. and O. Moav (2004). From Physical to Human Capital Accumulation: Inequality and the Process of Development. The Review of Economic Studies. (4)71: 1001-1026.

GPN (2001). GPN Global Labor Market Database: Korea. Global Policy Network

Golmuka, S. (1991). The Theory of Technological Change and Economic Growth. London and New York: Routledge,

Heston, A., R. Summers and B. Aten. Penn World Table Version 6.2. Center for International Comparisons of Production, Income and Prices at the University of Pennsylvania, September 2006.

Hofman, A. (1993). Economic Development in Latin America in the 20th Century - A Comparative Perspective. In A. Szirmai, B. Van Ark and D. Pilat (eds.), Explaining Economic Growth: Essays in Honour of Augus Madison. Armsterdam, London, New York, Tokyo: North Holland, 241-266.

Keller, W.(2001). International Technology Diffusion. Working paper, 5873. National Bureau of Economic Research.

Kim, J. and L. Lau (1994). The Sources of Economic Growth in the East Asian Newly Industrial Countries. Journal of Japanese and International Economics, (3)8: 235-271.

Kim, L. and R. Nelson (eds.) (2000). Technology, Learning and Innovation. Cambridge: Cambridge University Press.

King, R. G. and S. T. Rebelo (1993). Transitional Dynamics and Economic Growth in Neoclassical Model. The American Economic Review, (4)83: 908931. 
Kumar, K.B.(2003). Education and Technology Adoption in a Small Open Economy: Theory and Evidence. Macroeconomic Dynamics, (4)7: 586-617.

Krugman, P. (1994). The Myth of Asia's Miracle. Foreign Affairs, (6)73: $62-78$.

Lall, S. (2000). Technological Change and Industrialization in Asian Newly Industrializing Economies: Achievements and Challenges. In L. Kim and R. Nelson (eds.), Technology, Learning and Innovation. Cambridge: Cambridge University Press, 13-68.

Lau, L. and J. Park (2003). The Sources of East Asian Economic Growth Revisited. Working paper: Stanford University.

Le Van, C. and R.A. Dana, (2003). Dynamic programming in Economics. Dordrecht/Boston/London: Kluwer Academic Publishers.

Lucas, R.E. Jr. (1988). On the Mechanics of Economic Development. Journal of Monetary Economics, (1)22: 3-42.

Ministry of Labor and Social Security of China, (2005). Statistics, http://www.chinalaborwatch.org National Science Council (2007). Indicators of Science and Technology Taiwan, Taiwan.

Psacharopoulos, G. (1994). Returns to Investment in Education: A Global Update. World Development, (9)22: 1325-1343.

Ramsey F.(1928). A Mathematical Theory of Saving. Journal of Economic Theory, (152)38: 543-559.

Romer, P. (1987). Growth Based on Increasing Returns Due to Specialization. American Economic Review, (2)77: 56-62.

Romer, P. (1990). Endogenous Technological Changes. Journal of Political Economy, (5)98: S71-S102.

U.S. Department of State, http://www.states.gov 
Verspagen, B. (1991). A New Empirical Approach to Catching up or Falling behind. Structural Change and Economic Dynamics, (2)2: 359-380.

World Bank, World Development Indicators, www.worldbank.org/data

Young, A. (1995). The Tyranny of Number: Confronting the Statistical Realities of the East Asian Growth Experience. The Quarterly Journal of Economics, (3)110: 641-680. 